\title{
The Evaluation of Uterine Leiomyoma Prevalence and Its Effect on Cervical Length During Mid-Trimester Ultrasound Scan
}

\author{
DCihan KARADAĞa, \\ -Bertan AKAR ${ }^{b}$, \\ (1) Gökçenur GÖNENÇa, \\ DEray ÇALIŞKANa
}

aDepartment of Obstetrics and Gynecology, Okan University Faculty of Medicine, 'Department of Obstetrics and Gynecology İstinye University Faculty of Medicine, İstanbul, TURKEY

Received: 04 Sep 2019

Received in revised form: 27 Oct 2019

Accepted: 08 Nov 2019

Available online: 29 Nov 2019

\section{Correspondence:}

Cihan KARADAĞ

Okan University Faculty of Medicine, Department of Obstetrics and Gynecology, İstanbul, TURKEY

cihankaradag2000@ hotmail.com
Copyright ( $) 2019$ by Türkiye Klinikleri

\begin{abstract}
Objective: This study aims to investigate the effects of uterine leiomyomas' on cervical length in pregnant women during mid-trimester ultrasound scan. Material and Methods: In this study, 1908 pregnant women aged 18-44 years were evaluated via abdominal and transvaginal ultrasounds in the mid-trimester (18-24 weeks). The number, size, type and location of the leiomyomas were screened and recorded. Cervical length was measured transvaginally on an empty bladder. Short cervix was defined as lower than $25 \mathrm{~mm}$. Pregnant women with leiomyoma were compared with pregnant women without leiomyoma regarding cervical length and short cervix incidence. Results: Eighty (4.2\%) patients were diagnosed with uterine leiomyoma and the mean diameter of uterine leiomyomas was $31.4 \mathrm{~mm}$. The mean cervical length of the leiomyoma group was significantly lesser than that in pregnant women without leiomyomas $(\mathrm{p}=0.001)$. The number of women with a short cervix was higher in the leiomyoma group than the controls $(\mathrm{p}=0.001)$. There was a significant positive correlation between age and leiomyoma prevalence $(r=0.294, p=0.021)$. There was a significant negative correlation between myoma size and cervical length in women with only one leiomyoma $(r=-0.325, p=0.015)$. Conclusion: Pregnant women with leiomyoma have higher incidence of short cervix. Leiomyomas could negatively affect cervical length.
\end{abstract}

Keywords: Leiomyoma; cervical length; short cervix; pregnancy; ultrasound

I eiomyomas are the most common benign tumors of the female reproductive tract and have a prevalence of $30 \%$ to $70 \%$ among women of reproductive age. ${ }^{1}$ Leiomyomas are seen in about $3 \%-12 \%$ of pregnant women. ${ }^{2,3}$ Often, uterine leiomyomas are incidentally discovered during ultrasound examinations. ${ }^{4}$ Previous studies have shown increased obstetric complications in pregnant patients with leiomyomas. ${ }^{5}$

Leiomyomas are frequently observed in pregnancy and are concerning because of negative obstetric outcomes, such as increased risk of missed abortions, preterm birth, abruptio placenta, premature rupture of membranes (PPROM), malpresentation of fetus, dystocia, cesarean delivery, postpartum hemorrhage, and hysterectomy. ${ }^{6-8}$

There has been controversy regarding the relation between uterine leiomyomas and the increased risk of preterm birth. While many studies have reported an increased risk of preterm birth for pregnant women with leiomyomas; other studies have reported no relationship. ${ }^{7-12}$ The underlying mechanisms of preterm labor and leiomyomas remain unclear and previous studies have elucidated that a short cervix is a potential outcome in pregnant patients with leiomyomas. ${ }^{7,8}$ 
This study aims to investigate the effects of uterine leiomyomas on cervical length in pregnant women during mid-trimester ultrasound scan.

\section{MATERIAL AND METHODS}

\section{PATIENTS AND ETHICAL CONSIDERATIONS}

This study included 2061 pregnant women between the ages of 18-44, at mid-trimester (between 18 and 24 weeks of gestation) who underwent ultrasonography for mid-trimester ultrasound scan. This study was conducted at the outpatient clinic of Department of Obstetrics, Kocaeli University Hospital between January 2016 and January 2019. The local ethics committee of Kocaeli University School of Medicine approved the study. This study was conducted in accordance with the principles set forth in the Helsinki Declaration 2008. Written informed consent was taken from all participants. Women who had previously undergone cervical excisional procedures, had cervical cerclage during the present pregnancy, had multiple pregnancies, or who had uterine anomalies were excluded.

\section{MEASUREMENTS}

The obstetric and medical histories of the participants were obtained. The body mass index (BMI) was determined $\left(\mathrm{kg} / \mathrm{m}^{2}\right)$. An abdominal ultrasound was performed using a Voluson E8 device and 21 $\mathrm{MHz}$ transducer (GE Healthcare 9900 Innovation Drive Wauwatasa, WI 5322 U.S.A.) by the same perinatologist. The sonographer measured each leiomyoma for 3 times, and the maximum diameter was recorded in three perpendicular planes each time. The number, size, type and location of the leiomyomas were screened and recorded. Using sonography, the cervical length was measured transvaginally on an empty bladder. The sagittal view for each calculation was determined at the finding of triangular echolucency at the external cervical os, a $\mathrm{V}$-shaped notch at the internal os of cervix, and a faint line of echodensity between them..$^{13}$ The cervical length is evaluated at rest, and with transfundal pressure. Any change with pressure is noted. The shortest measurement of the cervical length is recorded. The patients with short cervix $(<25 \mathrm{~mm})$ were determined. ${ }^{14}$

The leiomyoma group consisted of pregnant women with at least one measured uterine leiomyoma and the control group consisted of pregnant women without any sonographically identified uterine leiomyoma.

\section{STATISTICAL ANALYSES}

SPSS 20.0 program was used to analyze the relationship between the variables in this research. The comparisons between the two groups were made by the Student t-test and Mann Whitney U test, where appropriate. The chi-squared test was used to compare categorical values. Pearson correlation test was used for the correlations between the variables. The statistical significance level was set at $\mathrm{p}<0.05$. All results were expressed as mean \pm standard deviation (SD).

\section{RESULTS}

Among 1908 patients, 80 (4.2\%) were diagnosed with uterine leiomyoma. Among these 80 patients, $56(70 \%)$ had only one leiomyoma, while 24 patients (30\%) had 2 or more leiomyomas. The mean leiomyoma diameter was $31.4 \mathrm{~mm}$ (range: $21 \mathrm{~mm}$ $122 \mathrm{~m}$ ). In total, 110 leiomyomas were detected in these 80 pregnant women; 45 (41\%) of them were localized anteriorly, 20 (18\%) of them were localized posteriorly, 22 (20\%) of them were localized laterally, and $23(21 \%)$ of them were fundal. Additionally, $74(67 \%)$ of them were intramural, 28 (26\%) of them were subserous and $8(7 \%)$ of them were submucosal.

The demographic data and ultrasound findings of the groups are shown in Table 1. The two groups were age and BMI matched. The gravidity of the leiomyoma group was higher. $(\mathrm{p}=0.026)$. There was no difference in the levels of parity and vaginal bleeding rates between the patients with and without leiomyoma.

The mean cervical length of the leiomyoma group was significantly lower than the pregnant women without any leiomyomas $(\mathrm{p}=0.001)$. The number of pregnant patients with a short cervix 


\begin{tabular}{|c|c|c|c|}
\hline & Leiomyoma $+(n=80)$ & No Leiomyoma $(\mathrm{n}=1.828)$ & $\mathrm{p}$ \\
\hline Maternal age (years) & $31.6 \pm 4.8$ & $30.9 \pm 3.8$ & 0.222 \\
\hline $\operatorname{BMI}\left(\mathrm{kg} / \mathrm{m}^{2}\right)$ & $27.9 \pm 2.1$ & $27.4 \pm 2.3$ & 0.342 \\
\hline Gravidity & $2.98 \pm 1.5$ & $2.48 \pm 1.3$ & 0.026 \\
\hline Parity & $1.12 \pm 1.2$ & $1.02 \pm 1.2$ & 0.146 \\
\hline Gestational age at ultrasound examination & $21.4 \pm 1.5$ & $21.3 \pm 1.7$ & 0.442 \\
\hline Vaginal bleeding in pregnancy & $11(13.8 \%)$ & $215(11.2 \%)$ & 0.216 \\
\hline Cervical length (mm) & $32.8 \pm 4.6$ & $34.6 \pm 4.8$ & 0.001 \\
\hline Short cervix (<25 mm) & $9(11.2 \%)$ & $60(3.1 \%)$ & 0.001 \\
\hline
\end{tabular}

BMI: Body mass index.

was higher in the leiomyoma group than the control group $(\mathrm{p}=0.001)$.

There was a significant positive correlation between the age of women and leiomyoma prevalence $(r=0.294, p=0.021)$, and there was a significant negative correlation between myoma size and cervical length in women with only one leiomyoma $(\mathrm{r}=-0.325, \mathrm{p}=0.015)$. The correlation between leiomyoma size and cervical length is shown in Figure 1.

\section{DISCUSSION}

In this study, we investigated the prevalence of uterine leiomyomas in pregnant women, and we evaluated the cervical length and incidence of a short cervix in pregnant women with leiomyoma. We found a shorter cervical length and higher incidence of a short cervix in pregnant women with leiomyoma. We also found a negative correlation between uterine leiomyoma size and cervical length in pregnant women.

Leiomyomas are the most common uterine tumors and originate from the smooth muscles of the uterus. Most uterine leiomyomas are asymptomatic and it is difficult to know the accurate prevalance of them. Today women could delay child-bearing, thus the incidence of uterine leiomyomas could increase and their effects to obstetric outcomes would be more important. Furthermore, previous studies have reported conflicting results regarding the prevalence of leiomyomas in pregnancy. In a prospective cohort study, Laughlin et al. evaluated

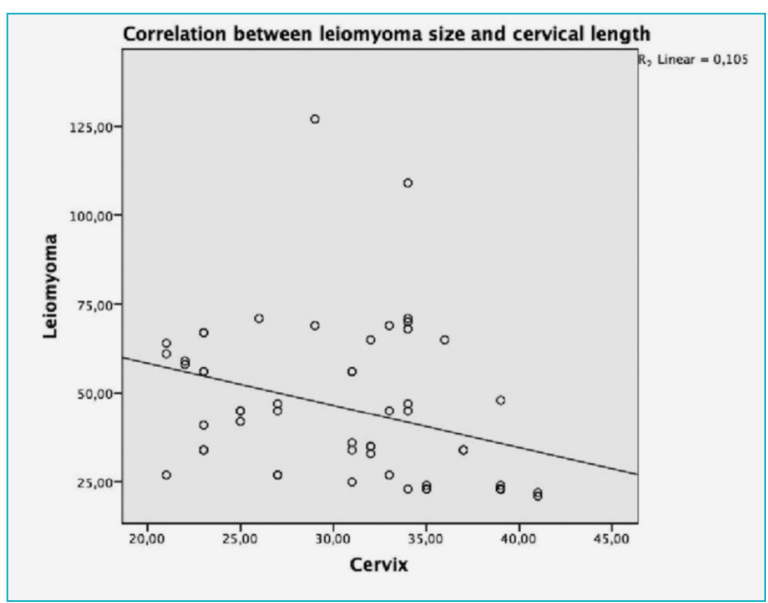

FIGURE 1: The correlation between leiomyoma size and cervical length.

4272 pregnant women and detected leiomyomas in 458 women (10.7\%). They reported a mean leiomyoma size of $23 \mathrm{~mm} .{ }^{3}$ In our study, we found a $3.9 \%$ prevalence rate of leiomyomas in pregnant women; the mean size was $31 \mathrm{~mm}$. Although the mean age of the cohort in their study was similar to ours, varying results between the studies may be due to racial differences between the cohorts. Laughlin et al. found a higher prevalence of leiomyomas in black women (18\%); on the other hand, our study did not include black women. We reported a larger mean size of leiomyomas than the previous study, which examined the women in the first trimester. ${ }^{3}$ In our study, we evaluated pregnant women in the second trimester and the mean size of leiomyomas may have increased due to the effects of pregnancy. 
Today, prevalence of leiomyoma in pregnancy is higher than in the past due to the advanced diagnostic methods which allows an early individuation and diagnosis, and increased age of pregnancy planning, that indicates a higher risk age for this. ${ }^{15,16}$ In our study, we found a positive correlation between age and leiomyoma prevalence, consistently with the findings of Marshall et al. ${ }^{17}$

Only few studies investigated the relation between uterine leiomyomas and short cervix in pregnant women. Blitz et al. investigated whether pregnant women with uterine leiomyoma are at higher risk for a short cervix. ${ }^{18}$ According to this retrospective study, they reported $5.1 \%$ leiomyomas prevalence in pregnant patients. In this study the authors evaluated the pregnant women with gestational age of 17-23 weeks and found significantly higher short cervix ( $<25 \mathrm{~mm}$ ) incidence (3.6\%) in pregnant patients with leiomyoma than healthy pregnant controls (1.5\%). They showed an association between the presence of uterine leiomyoma and increased risk of having short cervix. In another retrospective cohort study, Shavell et al. found a higher rate of short cervix (14.3\%) in women with uterine leiomyomas. ${ }^{8}$ Furthermore, they observed an increased rate of preterm birth in women with leiomyoma. However, they reported an increased prevalence of short cervix only in women with large uterine leiomyomas $(>5 \mathrm{~cm})$; that is, they found a $1.9 \%$ prevalence rate of short cervix rate in women with small leiomyomas. In our study, we found a short cervix rate of $11.2 \%$ in women with leiomyomas. Although Shavell et al. reported a higher rate of short cervix, our findings are similar with this study. They found a similar prevalence rate in women with leiomyomas $>5 \mathrm{~cm}$. However, the mean size of leiomyomas in our study was 31.4 $\mathrm{mm}$. We also found a negative correlation between uterine leiomyoma size and cervical length. This finding suggests that large uterine leiomyomas may contribute to a short cervix more than smaller ones. Leiomyomas may decrease the uterine distensibility, which may result in shortening of the cervix or preterm birth.

This study has some limitations that should be addressed. First, our study lacks obstetric outcomes of the pregnant women we included; that is, we do not know the preterm birth rates in our study population. Next, the study was mostly comprised of the patients who were referred to a single specialist. Hence, the results in this study represent the East Marmara region of Turkey, but may not represent the general Turkish population. Future studies should include the patients from multiple centers in Turkey and evaluate the obstetric outcomes.

\section{CONCLUSION}

The prevalence of uterine leiomyomas could increase with age. According to mid-trimester ultrasound results, $4.2 \%$ of pregnant women have leiomyomas. Pregnant patients with uterine leiomyoma have an increased risk of having short cervix. Leiomyomas could affect negatively cervical length and may cause a shortened cervix. Further studies with a large study population may clarify which leiomyomas cause decreases in cervical length and preterm birth with respect to number, size, type and location; therefore, recommendations on follow-up and birth management can be provided.

\section{Acknowledgements}

The English Language editing of this manuscript was done by Taylor Francis English Editing Service.

\section{Source of Finance}

During this study, no financial or spiritual support was received neither from any pharmaceutical company that has a direct connection with the research subject, nor from a company that provides or produces medical instruments and materials which may negatively affect the evaluation process of this study.

\section{Conflict of Interest}

No conflicts of interest between the authors and / or family members of the scientific and medical committee members or members of the potential conflicts of interest, counseling, expertise, working conditions, share holding and similar situations in any firm.

\section{Authorship Contributions}

Idea/Concept: Cihan Karadağ; Design: Eray Çalışkan; Control/Supervision: Eray Çalışkan; Data Collection and/or Pro- 
cessing: Bertan Akar; Analysis and/or Interpretation: Cihan

Karadağ; Literature Review: Gökçenur Gönenç; Writing the Ar- ticle: Cihan Karadağ; Critical Review: Cihan Karadağ; References

and Fundings: Gökçenur Gönenç; Materials: Bertan Akar.

\section{REFERENCES}

1. Okolo S. Incidence, aetiology and epidemiology of uterine fibroids. Best Pract Res Clin Obstet Gynaecol. 2008;22(4):571-88. [Crossref] [PubMed]

2. Stout MJ, Odibo AO, Graseck AS, Macones GA, Crane JP, Cahill AG. Leiomyomas at routine second-trimester ultrasound examination and adverse obstetric outcomes. Obstet Gynecol. 2010;116(5):1056-63. [Crossref] [PubMed]

3. Laughlin SK, Baird DD, Savitz DA, Herring $\mathrm{AH}$, Hartmann KE. Prevalence of uterine leiomyomas in the first trimester of pregnancy: an ultrasound screening study. Obstet Gynecol. 2009;113(3):630-5. [Crossref] [PubMed] [PMC]

4. De Vivo A, Mancuso A, Giacobbe A, Savast LM, De Dominici R, Dugo N, et al. Uterine myomas during pregnancy: a longitudinal sonographic study. Ultrasound Obstet Gynecol. 2011;37(3):361-5. [Crossref] [PubMed]

5. Coronado GD, Marshall LM, Schwartz SM. Complications in pregnancy, labor, and delivery with uterine leiomyomas: a populationbased study. Obstet Gynecol. 2000;95(5):764-9. [Crossref] [PubMed]

6. Lee HJ, Norwitz ER, Shaw J. Contemporary management of fibroids in pregnancy. Rev Obstet Gynecol. 2010;3(1):20-7. [PubMed]
7. Chen $\mathrm{YH}$, Lin HC, Chen SF, Lin HC. Increased risk of preterm births among women with uterine leiomyoma: a nationwide population-based study. Hum Reprod. 2009;24(12):3049-56. [Crossref] [PubMed]

8. Shavell VI, Thakur M, Sawant A, Kruger ML, Jones TB, Singh M, et al. Adverse obstetric outcomes associated with sonographically identified large uterine fibroids. Fertil Steril. 2012;97(1):107-10. [Crossref] [PubMed]

9. Qidwai GI, Caughey AB, Jacoby AF. Obstetric outcomes in women with sonographically identified uterine leiomyomata. Obstet Gynecol. 2006;107(2 Pt 1):376-82. [Crossref] [PubMed]

10. Vergani $P$, Ghidini A, Strobelt N, Roncaglia N, Locatelli $A$, Lapinski $R H$, et al. Do uterine leiomyomas influence pregnancy outcome? Am J Perinatol. 1994;11(5):356-8. [Crossref] [PubMed]

11. Vergani P, Locatelli A, Ghidini A, Andreani M, Sala F, Pezzullo JC. Large uterine leiomyomata and risk of cesarean delivery. Obstet Gynecol. 2007;109(2 Pt 1):410-4. [Crossref] [PubMed]

12. Roberts WE, Fulp KS, Morrison JC, Martin JN $\mathrm{Jr}$. The impact of leiomyomas on pregnancy. Aust N Z J Obstet Gynaecol. 1999;39(1):437. [Crossref] [PubMed]
13. Goldenberg RL, lams JD, Miodovnik M, Van Dorsten JP, Thurnau G, Bottoms S, et al. The preterm prediction study: risk factors in twin gestations. Am J Obstet Gynecol. 1996;175(4 Pt 1):1047-53. [Crossref] [PubMed]

14. Berghella V, Roman A, Daskalakis C, Ness A, Baxter JK. Gestational age at cervical length measurement and incidence of preterm birth. Obstet Gynecol. 2007;110(2 Pt 1):311-7. [Crossref] [PubMed]

15. Bałoniak B, Słomko Z, Malewski Z, Drews K [The incidence of uterine leiomyomas in pregnancy and their influence upon its course]. Ginekol Pol. 2002;73(4):260-5. [PubMed]

16. Cooper NP, Okolo S. Fibroids in pregnancy-common but poorly understood. Obstet Gynecol Surv. 2005;60(2):132-8. [Crossref] [PubMed]

17. Marshall LM, Spiegelman D, Barbieri RL, Goldman MB, Manson JE, Colditz GA, et al. Variation in the incidence of uterine leiomyoma among premenopausal women by age and race. Obstet Gynecol. 1997;90(6):967-73. [Crossref] [PubMed]

18. Blitz MJ, Rochelson B, Augustine S, Greenberg $\mathrm{M}$, Sison $\mathrm{CP}$, Vohra N. Uterine fibroids at routine second-trimester ultrasound survey and risk of sonographic short cervix. J Matern Fetal Neonatal Med. 2016;29(21):3454-60. PMID: 26653679. [PubMed] 